\title{
Meiotic Chromosome Contacts as a Plausible Prelude for Robertsonian Translocations
}

\author{
Sergey Matveevsky ${ }^{1, *(\mathbb{D}}$, Oxana Kolomiets ${ }^{1}$, Aleksey Bogdanov ${ }^{2} \mathbb{D}$, Elena Alpeeva ${ }^{2}$ and \\ Irina Bakloushinskaya ${ }^{2}$ (D) \\ 1 Vavilov Institute of General Genetics, Russian Academy of Sciences, 119991 Moscow, Russia; \\ olkolomiets@mail.ru \\ 2 Koltzov Institute of Developmental Biology, Russian Academy of Sciences, 119334 Moscow, Russia; \\ bogdalst@yahoo.com (A.B.); alpeeva_1@mail.ru (E.A.); irina.bakl@gmail.com (I.B.) \\ * Correspondence: sergey8585@mail.ru; Tel.: +7-499-135-53-61; Fax: +7-499-132-89-62
}

Received: 28 February 2020; Accepted: 31 March 2020; Published: 2 April 2020

\begin{abstract}
Robertsonian translocations are common chromosomal alterations. Chromosome variability affects human health and natural evolution. Despite the significance of such mutations, no mechanisms explaining the emergence of such translocations have yet been demonstrated. Several models have explored possible changes in interphase nuclei. Evidence for non-homologous chromosomes end joining in meiosis is scarce, and is often limited to uncovering mechanisms in damaged cells only. This study presents a primarily qualitative analysis of contacts of non-homologous chromosomes by short arms, during meiotic prophase I in the mole vole, Ellobius alaicus, a species with a variable karyotype, due to Robertsonian translocations. Immunocytochemical staining of spermatocytes demonstrated the presence of four contact types for non-homologous chromosomes in meiotic prophase I: (1) proximity, (2) touching, (3) anchoring/tethering, and (4) fusion. Our results suggest distinct mechanisms for chromosomal interactions in meiosis. Thus, we propose to change the translocation mechanism model from 'contact first' to 'contact first in meiosis'.
\end{abstract}

Keywords: Ellobius alaicus; translocation; non-homologous chromosome connections; meiosis; synaptonemal complex

\section{Introduction}

Chromosomal stability, number and positioning are essential factors for correct genome functionality and inheritance. At the end of 19th century, Rabl hypothesized the non-random, three-dimensional location of chromosomes in the nucleus, whereas in the last two decades, these observations have been advanced with data from advanced technological methods, including fluorescence in situ hybridization (FISH), immunocytochemistry and others [1-3]. Information on the tissue-specific positioning of chromosomes has revealed functional nuclear regulation [4,5], or altered states in cancer cells [6,7]. Chromosomal changes at the individual development are usually highlighted as catastrophic genomic events, while such chromosomal alterations often result in carcinogenesis and infertility $[8,9]$. Genomes of carcinogenetic cells are highly dynamic, and in some cases, chromosomal changes, either induced or spontaneous, lead to therapeutic resistance [10]. Chromoanagenesis, encompasses chromothripsis, chromoanasynthesis and chromoplexy, and was recently described as a possible mechanism contributing to chromosomal evolution [11-13]. Even though a rearranged genome may suffer maladaptive modifications, some variations are beneficial for organisms or species in terms of advantageous natural selection. Karyotypic diversity, structural variations of autosomes and sex chromosomes exemplify the importance of chromosomal changes throughout evolution [14-19]. 
Distinct drivers for chromosomal change have been identified, e.g., mobile Penelope elements implicated in Drosophila speciation [20], LINE-1 elements in mammals [21], and noncoding RNAs [22] etc. These factors destabilize genomes, initiate DNA damage, and provoke the abnormal linking of chromosomes. At least two translocation models based on non-random chromosome distribution in the nucleus have been proposed [23].

An initial step in "breakage-first" models are double-strand breaks (DSBs). Then potential partners occasionally tie up and produce changed chromosomes, which can obtain distinct fragments of non-homologous chromosomes, up to the whole arm, e.g., Robertsonian translocations (Rbs) or Whole-Arm Reciprocal Translocations (WARTs) [23]. Translocation probability rates could be higher if chromosomes were located close to each other in the nuclear space [24]. For intermingling chromosomes, DSBs in contact zones can lead to non-homologous linking and translocations [25,26]. In this context, the evolutionary integrative breakage model [27] stressed determining the genomic distribution of evolutionary breakpoints due to particular DNA sequence composition and the nucleome, combined with alteration of gene expression due to genome reshuffling.

In the 'contact-first' models, chromosomes should be broken, but DSBs start in colocalized chromatids inside specific protein complexes [28]. Firstly, chromosomes come together, then undergo DSBs and join with other partners. Chromosome region mobility is different during the cell cycle; it is higher in the early G1 phase, but decreases in the S phase. In an interphase nucleus, chromatin status, positioning, and cytoskeleton mechanical forces, all influence chromosome movement [29]. The combined variant of both models was also proposed. If DSBs occur in G1 and are not repaired until G2, they may cluster and form translocations [30].

In all models, the fate of small acrocentric chromosomal arms is uncertain; but most probably, they are eliminated. It is important to highlight these models were developed for interphase nuclei when chromosomes were decondensed and occupied specific chromosomal territories. Moreover, the tissue-specific positioning of chromosomes in interphase nuclei [31], enables the formation of distinctive carcinogenic translocations [8], which better fit the first model.

When we investigate the altered three-dimensional organization of somatic cells with re-arranged chromosomes, we cannot immediately determine the evolutionary consequences. How will such translocations pass to the next generations? Therefore, we must look for genome rearrangements in the germline. De novo chromosome rearrangements can arise during germ cell proliferation, meiosis, and in haploid sperm or eggs [32]. Any rearrangement provoking genomic instability may be beneficial for diversification and genetic speciation.

A specific fusion between acrocentric chromosomes, ended by metacentric chromosomes was first described by Robertson [33], and later named Robertsonian translocations (Rbs). The frequency of such translocations in humans is high: approximately 1 in 1000 individuals [34]. The most common $\operatorname{rob}(13 q 14 q)$ and $\operatorname{rob}(14 q 21 q)$ translocations originate during oogenesis [35]. A breakpoint diversity exemplified distinct ways for $\mathrm{Rb}$ formation, the significant input of the pre-meiotic replication and proper meiotic recombination [36,37]. Probable mechanisms for the formation of Rbs involving telomere changes were suggested [38]. One of the potential mechanisms may be a loss of p-arm telomeres when chromosome breakage occurs within minor satellite sequences [39,40]; another way is a fusion without any losses, and inactivation of telomeres [41]; the one more way may operate via the deletion/inactivation of the telomerase RNA gene which induces telomere shortening [42]. Data on meiosis are scarce and are limited to non-homologous end joining (NHEJ) in mouse spermatocytes after gamma radiation [43], however telocentric chromosome associations in the pachytene are observed for Mus domesticus [44].

The high frequency of translocations in humans and the evolutionary input of Rbs requires exploration of non-model species to reveal origin and maintenance mechanisms. Several mammalian species have demonstrated natural variability's in chromosomal numbers, including Rbs. Mus, Sorex, Ellobius species, and some others exhibit changes in diploid numbers, along with stable fundamental numbers due to whole branch fusions [45-48]. Recently, using chromosome painting, we 
described karyotype structures in three cryptic Ellobius species, E. talpinus, E. tancrei, and E. alaicus; we demonstrated a homology of re-arranged chromosomes, and showed the existence of XX sex chromosomes in males and females [49-51]. We hypothesized that a neocentromere origin in one pair of chromosomes was an initial disturbance event for the E. tancrei ( $2 n=54-30)$ genome, in contrast to stable E. talpinus $(2 \mathrm{n}=54)[49,52]$. E. alaicus is very close to E. tancrei, a translocation $\mathrm{Rb}(2.11)$ emerged in both species; other Rbs are species-specific ones. E. alaicus demonstrates rapid chromosomal changes in nature, such as the fixation of Rbs in the large population in the Pamir-Alay [50]. In this study, we analyzed the meiotic sustainability of species with rapidly evolving genome.

\section{Materials and Methods}

\subsection{Material and Mitotic Chromosomes}

We used samples of 6 specimens of E. alaicus, kept in the cytogenetic collection (a part of the Joint collection of wildlife tissues for fundamental, applied and environmental researches of the Koltzov Institute of Developmental Biology RAS, Core Centrum of the Koltzov Institute of Developmental Biology RAS, state registration number 6868145). Two males and two females (collection numbers; $27353,27357,27354,27356)$ were karyotyped using bone marrow suspensions [53]. Tissue from another male (27532) and female (27351) were also used to derive somatic cell cultures. C-band staining of mitotic metaphase plates was performed according to Sumner [54].

We followed international, national, and institutional guidelines for animal care. Studies were approved by the Ethics Committee for Animal Research of the Koltzov Institute of Developmental Biology RAS and the Vavilov Institute of General Genetics RAS.

\subsection{Cell Culture}

Chondrocyte and fibroblast cell lines were obtained from the Cell culture collection of the Koltzov Institute of Developmental Biology RAS. Chondrocytes were cryopreserved after the first subcultivation and fibroblasts after the third subcultivation and were stored at $-196{ }^{\circ} \mathrm{C}$ in liquid nitrogen using cultivation media with $10 \%$ DMSO for cryopreservation. Karyotype evaluation was performed after the cells were recovered after freezing.

\subsection{Meiotic Chromosome Studies and Immunostaining}

Samples from three E. alaicus $(27352,27353$ and 27357) adult males were used for the meiotic study. Synaptonemal complex (SC) preparations were made and fixed according to Peters et al. [55], with some modifications [56].

Primary antibodies used for immunostaining: rabbit anti-synaptonemal complex protein 3 (SYCP3) antibody (diluted 1:250, Abcam, Cambridge, UK); human anti-centromere Calcinosis Raynaud's phenomenon, Esophageal dysmotility, Sclerodactyly, and Telangiectasia (CREST) antibody (CREST, 1:250, Fitzgerald Industries International, USA); mouse anti-phospho-histone H2AX (diluted 1:250-500, Abcam) (also known as $\gamma \mathrm{H} 2 \mathrm{AFX})$; rabbit anti-H3K9me3 antibody (1:100, Abcam; kindly provided by Dr. Jesus Page).

As secondary antibodies we used goat anti-rabbit IgG, Alexa Fluor 488-conjugate (Invitrogen, Carlsbad, CA, USA); goat anti-human IgG, Alexa Fluor 546-conjugate (Invitrogen); goat anti-mouse IgG, Alexa Fluor 546-conjugate (Invitrogen, USA) (diluted 1:250-500). Slides were washed in phosphate-buffered saline (PBS) and placed into Vectashield, with 4',6-diamidino-2-phenylindole (DAPI) (Vector Laboratories, USA). Slides were analyzed using a fluorescence light microscope, Axio Imager D1 (Carl Zeiss, Jena, Germany). Immunostaining was described previously [57,58]. We immunostained H3K9me3 histones using two approaches; 1) the first round of SYCP3 staining, then a second round- $-\mathrm{H} 3 \mathrm{~K} 9 \mathrm{me} 3$ or 2) the first round of $\mathrm{H} 3 \mathrm{~K} 9 \mathrm{me} 3$, then a second round of SYCP3 staining.

SCs measurements in 41 spermatocytes were performed using the MicroMeasure program (Colorado State University, CO, USA). 


\section{Results}

\subsection{Mitotic Chromosomes and SC Karyotype of E. alaicus}

All animals demonstrated normal for E. alaicus karyotypes; $2 \mathrm{n}=52$. the fundamental number of chromosome arms (NF) was 56 (Figure S1a-f), consisting of one pair of submetacentrics (№7), characteristic of E. tancrei and E. alaicus, and one pair of large Robertsonian metacentrics 2(Rb2.11), typical of E. alaicus [50]. Mitotic metaphases from bone marrow suspensions showed no visible alterations (Figure S1b). Mitotic metaphases from fibroblast cultures demonstrated a stable karyotype in one male (Figure S1a), and a small number of deviations in one female, i.e., associations and polyploid cells. In chondrocyte cultures of the same specimens, more associations and polyploid cells were identified in female cells (Figure S1d-f), alongside with a large number of micronuclei, disturbed anaphases and massive chromosomal changes (Figures S1g and S2).

A total of 302 spermatocytes at different prophase I stages in three males were analyzed. As expected, in the pachytene stage we revealed 25 fully synapsed autosomal bivalents (large Robertsonian metacentric $\mathrm{Rb}(2.11)$ ), one mid-size submetacentric №7 with neocentromere [49,52]; 23 acrocentrics and an XX sex bivalent (Figure 1), formed by two large acrocentrics. Analyzing large cell numbers made it possible to distinguish a range of gradually decreasing in size acrocentrics.

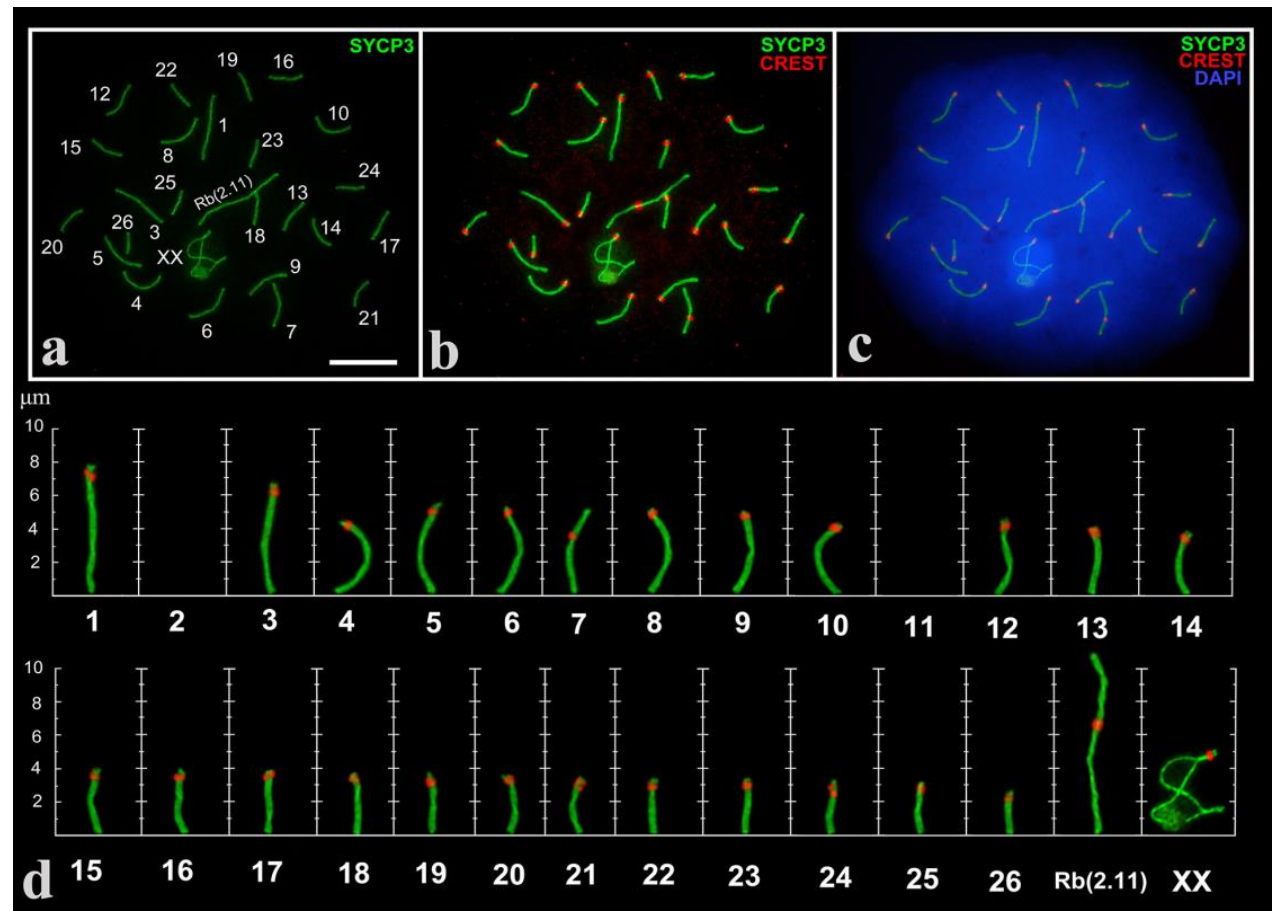

Figure 1. Pachytene spermatocyte $(\mathbf{a}-\mathbf{c})$ and synaptonemal complex (SC) karyotype (d) of the Alay mole vole, E. alaicus. SCs were immunostained with antibodies against synaptonemal complex protein 3 (SYCP3) (green) and centromeres-with antibodies to kinetochores (Calcinosis Raynaud's phenomenon, Esophageal dysmotility, Sclerodactyly, and Telangiectasia (CREST), red). The 4',6-diamidino-2-phenylindole (DAPI)-stained the chromatin (blue). SC numbers corresponded to the metaphase karyotype. $\mathrm{Rb}(2.11)$-Robertsonian submetacentric. Chromosome №7 is non-Robertsonian submetacentric. XX-male sex chromosomes. Bar $(\mathbf{a}-\mathbf{c})=5 \mu \mathrm{m}$.

\subsection{Prophase I Stages in E. alaicus}

All prophase I stages were demonstrated for E. alaicus. Thin short SYCP3 fragments and SYCP3 conglomerates were formed in the leptotene stage (Figure 2a). In the early zygotene stage, long axial elements were visible, and SYCP3 blocks were kept (Figure 2b). As the zygotene progressed, the axial elements of homologous chromosomes began to contact each other (Figure S3), and synapsed more 
frequently from telomere areas to the central part (Figure 2c), less often in the opposite way (Figure 2d). In the pachytene stage, chromosomes were completely synapsed (Figure $2 \mathrm{f}$ ). In the diplotene stage, chromosome desynapsis might be different within a single cell, from telomere sites to the center, or vice versa (Figure 2g). Then SYCP3 degraded (Figure $2 \mathrm{~h}$ ), and it was preserved as dots in the diakinesis stage (Figure 2i).

Sex $(X X)$ chromosomes from early to mid zygotene were detected as separate axial elements (Figure S3). From the mid-late zygote, the XX chromosomes became well visible (Figure 2c). The sex bivalent is similar to those of the cryptic species, E. talpinus [59] and E. tancrei [60,61]. In the middle pachytene, the XX-bivalent was usually shifted to the periphery of the meiotic nucleus and had two telomeric synaptic regions, a wide asynaptic region, and chromatin bodies on axial elements (Figure 2f). It should be noted that sometimes chromatin (nucleolus-like) bodies in sex bivalents were SYCP3-positive (Figure 1, Figure 2e,f), which has not been previously observed for the other two cryptic species and E. alaicus $(2 \mathrm{n}=48)$ from the Pamir-Alay [50].
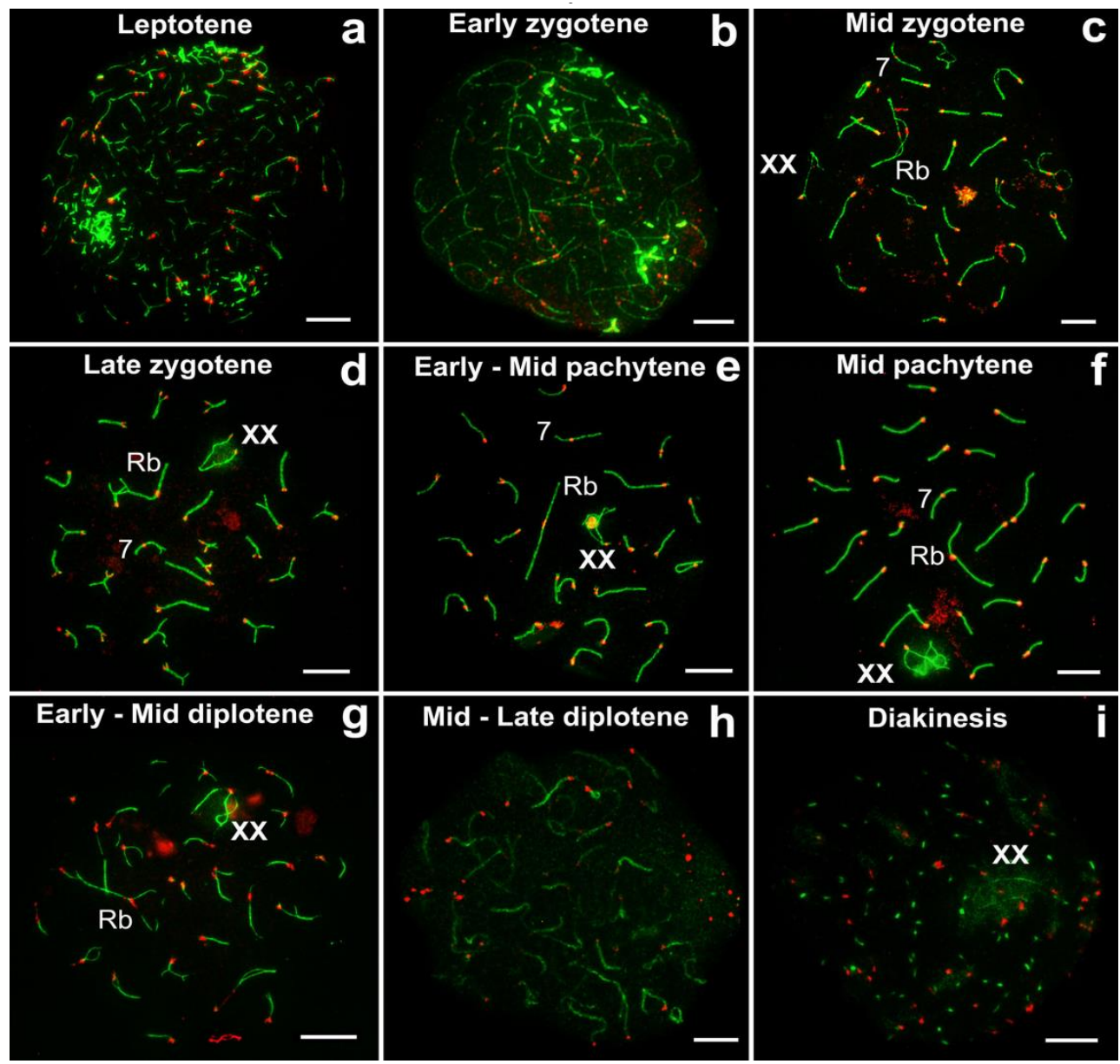

Figure 2. Prophase I stages in E. alaicus males. Axial/lateral elements were identified using anti-SYCP3 antibodies (green) and kinetochores (red) using CREST. During the leptotene stage, numerous thin SYCP3 fragments and SYCP3 conglomerates were formed (a), formed axial elements (b) were visible in the zygotene. Chromosome synapsis began with either distal (telomeric) (c) or central chromosome parts (d). At the pachytene stage, 25 autosomal SCs and sex (XX) bivalents were formed (e,f). The XX bivalent demonstrated synapsis at telomeric areas and asynapsis at the central region $(\mathbf{e}, \mathbf{f})$. In the mid-late diplotene, desynapsis progressed from both the central and telomeric areas (g). SYCP3 was degraded (h) and retained as dots (i). Rb-Robertsonian submetacentric. Chromosome 7 is non-Robertsonian submetacentric. Bar $(\mathbf{a}-\mathbf{i})=5 \mu \mathrm{m}$. 


\subsection{Types of Non-Homologous Acrocentric Connections}

Various non-homologous chromosome contacts were identified in meiotic prophase I, during zygotene-early pachytene stages. We revealed at least four sequential contact and link types of chromosomes (Figure 3, Figure 4, Figure 5, Figure 6, Figure 7).

\subsubsection{Proximity}

Acrocentrics occupied spatial positions, intending to get their centromeres closer (pink squares and pink numbers of chromosomes in Figure 3, Figure 7, Figures S4 and S5). The distance between the chromosomes was about 1-2 microns. Centromere regions of chromosomes were located around the H3K9me3-domain (Figure 6 and Figures S5-S7). This type precedes true meiotic contacts (see the following types). This 'proximity' type was somewhat subjective, because it can easily be confused with closely located chromosomes.

\subsubsection{Touching}

Acrocentrics moved closer to each other. In each contact acrocentric, one axial element of the short arm was extended, reaching out to one another as if touching each other with their ends (blue squares and blue numbers of chromosomes in Figure 3, Figure 5, Figure 7, Figures S4 and S5). Usually, the distance between the chromosomes is less than 1 micron.

\subsubsection{Anchoring/Tethering}

One of the axial elements in the short arms of non-homologous acrocentrics were linked to each other by SYCP3-filament (yellow squares and yellow numbers of chromosomes in Figure 3, Figure 4, Figure 5, Figure 7, Figures S4 and S5). Other axial elements of the short arms of the two non-homologous partners were not connected (see blue arrowheads in Figures 4 and 5c).

\subsubsection{Fusion}

The other two axial elements in the short arm of the non-homologous acrocentrics were tightly adjacent to each other, or possibly connected entirely. The two acrocentrics likely represented a single bivalent with two centromeres (Figure 4e,f, Figure $5 \mathrm{c}$ ). Centromeric regions were closer to each other compared to other connection types. Such dicentric bivalents were observed in some low-chromosomal forms in E. tancrei (Figure 7 and Figure S8).

Such linkage was evidenced by immunostaining; two thin SYCP3-positive filaments (Figure 4e,f). The difference between 'anchoring/tethering' (see filaments between chromosomes 5 and 6 in Figure S4e) and 'fusion' (Figure 4e,f; see chromosomes 14 and 18 in Figure S4e) can be determined by the presence of a complete bridge, with a short distance between two contacting non-homologous chromosomes. In all cases, the contact was made by the short arms of acrocentric chromosomes by SYCP3-filaments (see enlarged fragments of cells; Figure 4).

$51 \%$ of pachytene cells had meiotic contacts including 'touching', 'anchoring/tethering' and 'fusion' types and excluding 'proximity' (Figure 5a). The patterns of proportion of different connection types were similar in three males: the number of 'touching' was greater than the number of 'anchoring/tethering', the number of 'fusion' was less than two other types (Figure 5b). The 'fusion' type was not found in one male, №27353 (Figure 5b). The rarity of 'fusion' type may be due to the fact that more molecular events should precede the joining/fusion of the axial elements of the short arms of two non-homologous acrocentrics.

Chromosome combinations in pachytene spermatocytes of E. alaicus were numerous. We were unable to determine the trend in the frequencies of contact between certain chromosomes. However, chromosomes 1,4,5,20-22 came into contact more often. For example, chromosome №1, which was the most regularly seen in all three types of true interactions ('touching', 'anchoring/tethering', and 'fusion'). $\mathrm{Rb}(1.3)$ was described in E. alaicus with $2 \mathrm{n}=50$ [50]. 


\subsection{Histone H3K9me3 in Prophase I and Meiotic Chromosomes Contacts}

We investigated H3K9me3 (trimethylation of H3 lysine 9) immunolocalization and distribution in contacting chromosomes. $\mathrm{H} 3 \mathrm{~K} 9 \mathrm{me} 3$ is an epigenetic marker for heterochromatin allocation in prophase I [62].

During the zygotene stage, large clouds of $\mathrm{H} 3 \mathrm{~K} 9 \mathrm{me} 3$ were localized at pericentromeric regions of axial elements, or at fully formed SCs (Figure S6a-c). In the pachytene stage, clouds of H3K9me3 were reduced in size and were clearly localized to SC pericentromeric regions (Figure 6a-c, Figure S6d-i). $\mathrm{Rb}$-metacentrics had minimal H3K9me3 levels in the centromeric region (Figure 6a-c, Figure S6d-i), or were absent. Non-Robertsonian submetacentric №7 did not demonstrate clear H3K9me3 signals in all studied cells (Figures S6e-h and S7a-c). H3K9me3 usually shrouded one of the axial elements, and a chromatin body inside the sex bivalent (XX) (Figure 6a-d); less often H3K9me3 covered it entirely (Figure S5g,h), whilst $\gamma \mathrm{H} 2 \mathrm{AFX}$ totally enclosed XX (Figures $6 \mathrm{c}$ and 3b,e). A more detailed description of XX sex chromosomes in E. alaicus will be discussed in future work.

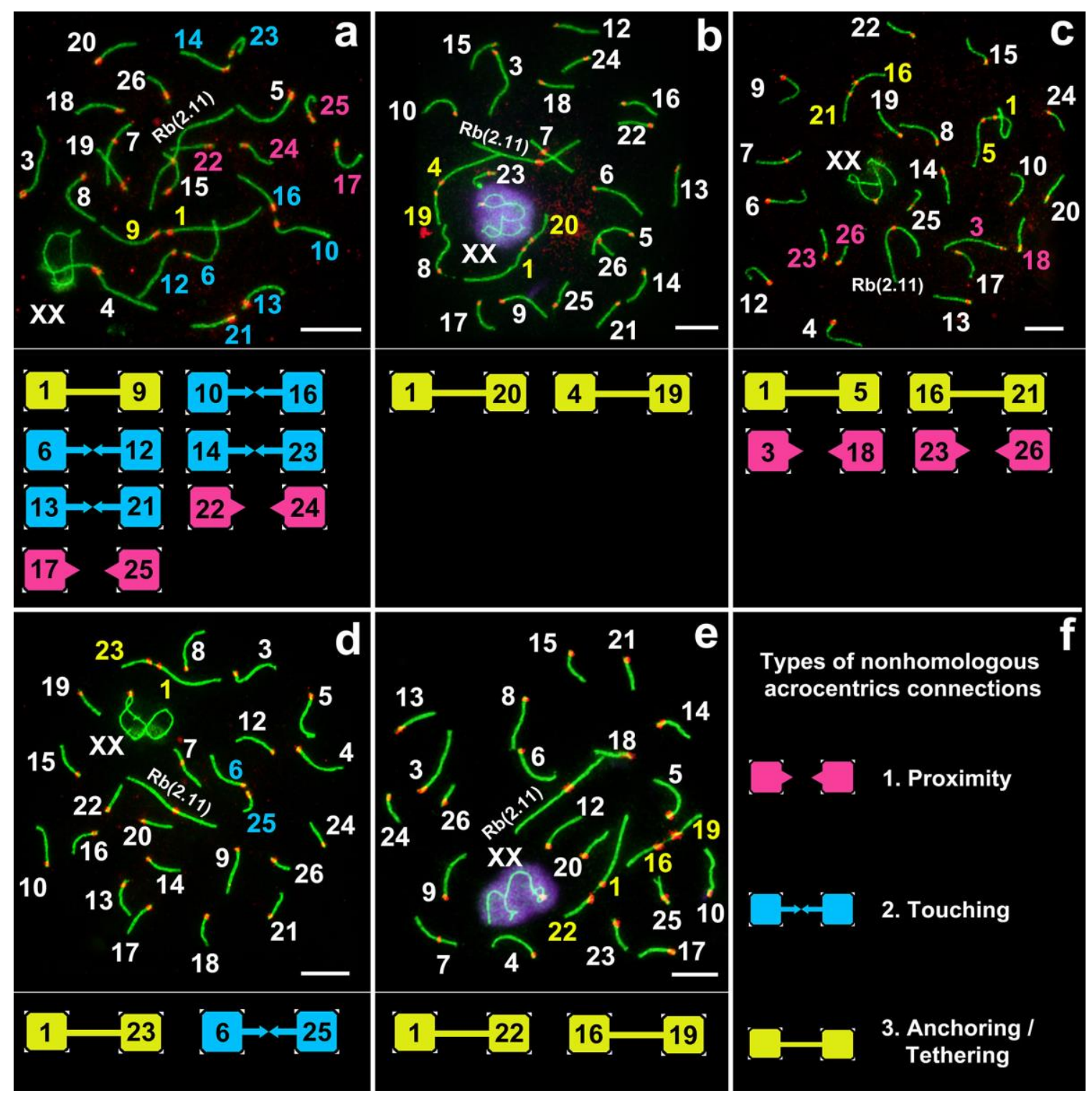

Figure 3. Different chromosome combinations in pachytene spermatocytes of E. alaicus (a-f). Axial elements were identified using anti-SYCP3 antibodies (green), kinetochores using CREST antibodies (red), and anti- $\gamma \mathrm{H} 2 \mathrm{AFX}$ (violet) was used as a marker of chromatin inactivation. Pink, blue, and yellow squares correspond to different types of non-homologous acrocentric connections (f). Bar $(\mathbf{a}-\mathbf{e})=5 \mu \mathrm{m}$. 

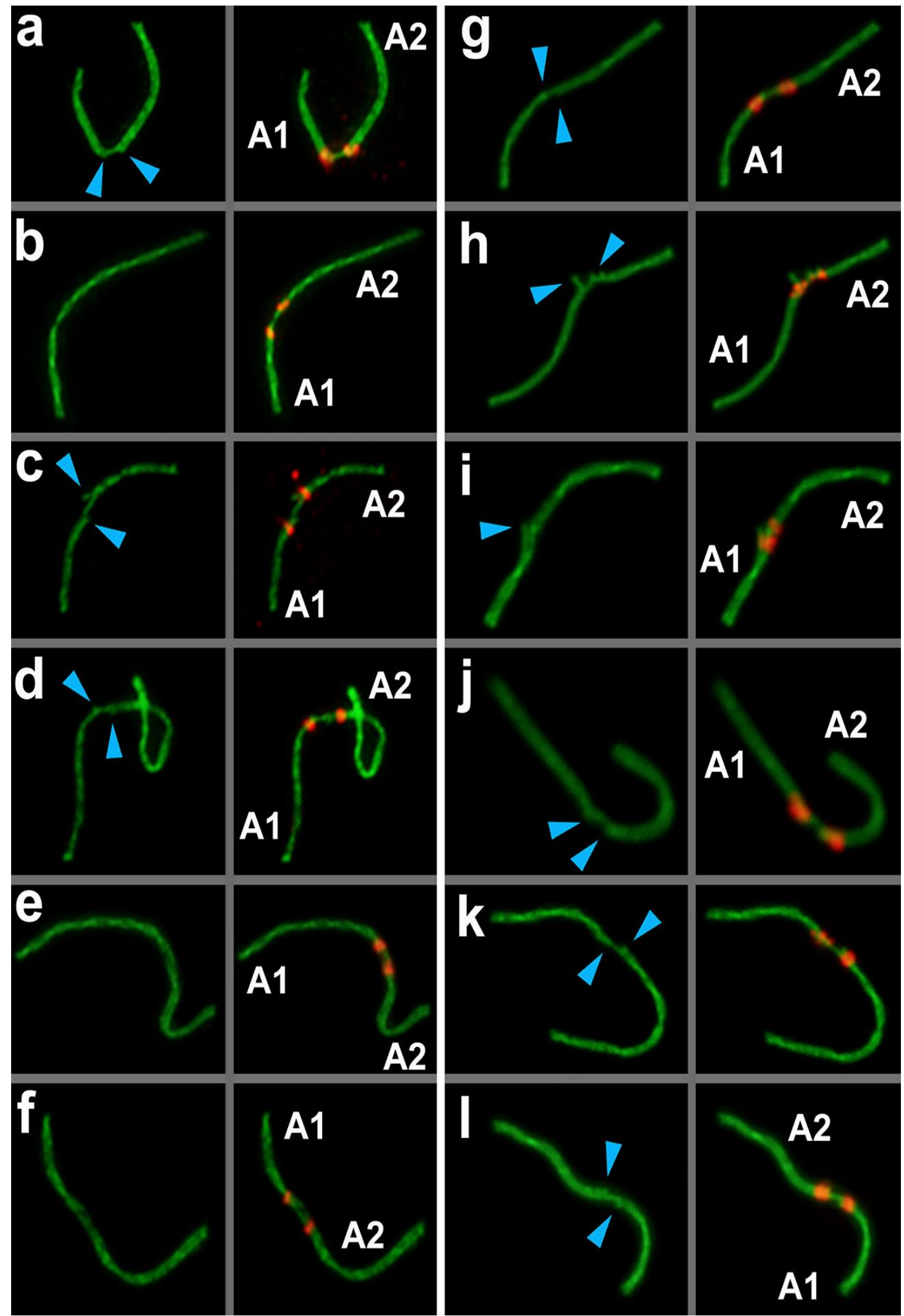

Figure 4. Anchoring/tethering and fusion of non-homologous acrocentric chromosomes in E. alaicus spermatocytes (a-1). Lateral elements were identified using anti-SYCP3 antibodies (green), and CREST antibodies for kinetochores (red). A1 and A2-contacting non-homologous acrocentrics. Blue arrowheads show the free ends of lateral elements of non-homologous acrocentrics. 
In non-homologous acrocentric contacts, $\mathrm{H} 3 \mathrm{~K} 9 \mathrm{me} 3$ was involved in varying volumes, usually in centromeric regions. We detected a large H3K9me3 cloud between chromosomes at the 'proximity' type (pinks points in Figure $6 \mathrm{a}, \mathrm{c}, \mathrm{e}-\mathrm{g}, \mathrm{i})$. For closer chromosome contacts, i.e., 'touching' and 'anchoring/tethering', H3K9me3 distribution ranged from average to insignificant (small) (yellow points in Figure 6a,d,e,g,i). If contacts involved shorter and longer acrocentrics, H3K9me3 signals were located closer to centromeric regions of shorter acrocentrics (Figure $6 \mathrm{~g}$,i). For other cases, H3K9me3 signals were clearly identified between the two centromeres of contacting chromosomes (Figure 6d,h).

\subsection{Mitotic Cells}

In contrast to meiotic cells demonstrating 'touching', 'anchoring', and 'fusion' of different acrocentrics during meiotic prophase I (Figure 5), in mitotic metaphases, we detected a single association in most cells, which were similar to the 'fusion' type. In total, we checked 693 cells: 532 cells had normal karyotype, 32 cells demonstrated chromosomal associations (5.6\%), and 126 were aberrant ones (micronuclei, polyploid cells, disturbed anaphases, chromothripsis, etc.). C-banding exposed small blocks of pericentromeric heterochromatin and several intercalary blocks (for two pairs of acrocentrics) (Figure S1c). Small blocks of C-heterochromatin were visible in associated chromosomes, but such blocks were not always merged.

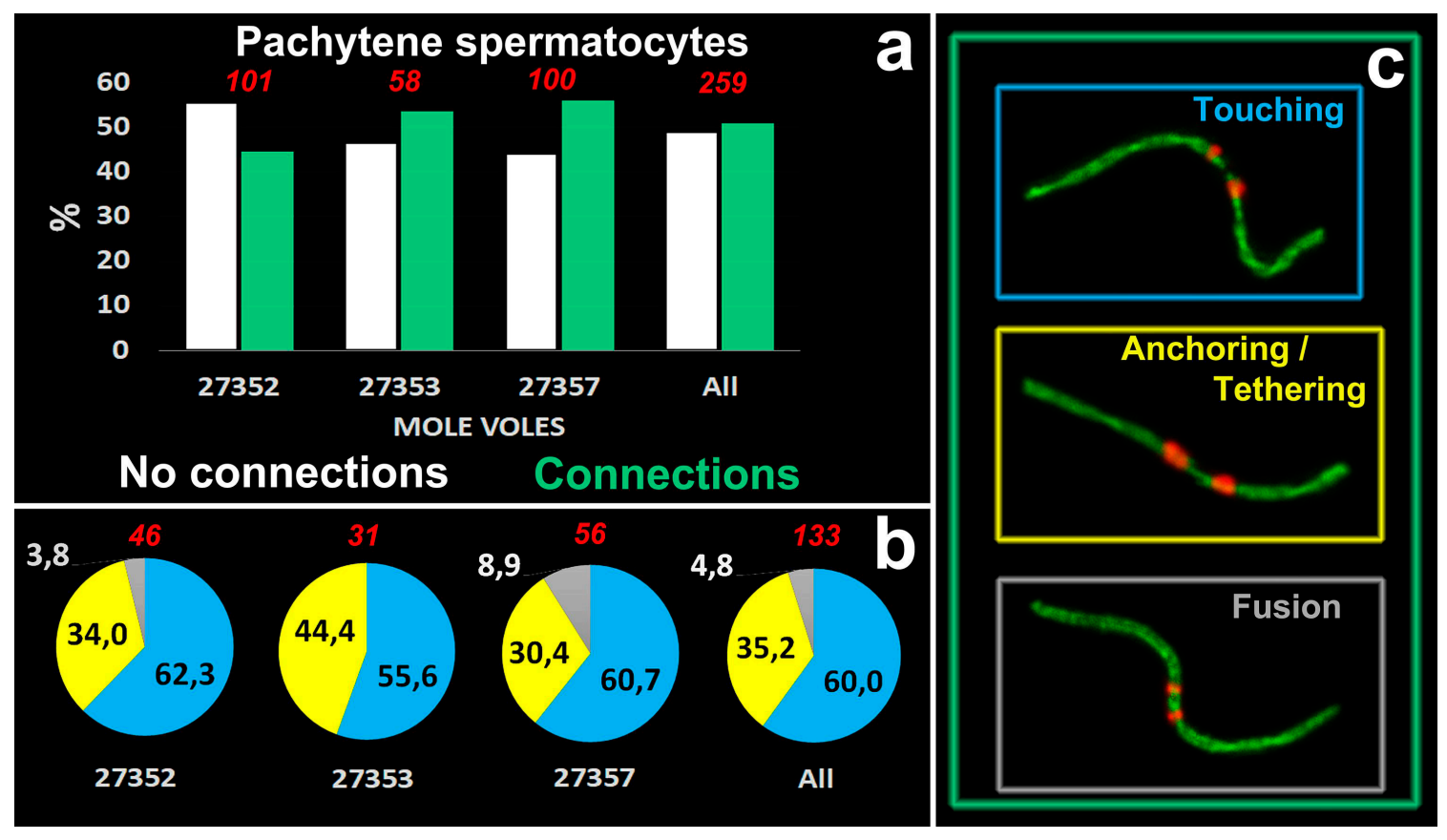

Figure 5. Quantitative characteristics of meiotic contacts in E. alaicus. (a). The diagram shows the percentage of pachytene cells with or without meiotic connections in three mole vole males (№27352, 27353, 27357). 'Touching', ' anchoring/tethering' and 'fusion' types were counted in cells with connections only. (b). Proportions of connection types. Blue color corresponds to 'touching', yellow-to 'anchoring/tethering' and gray-to "fusion". Red numbers are counted pachytene spermatocytes (a,b). (c). Types of contacts that are included in the diagrams. The color of the frames corresponds to the types of contacts $(\mathbf{b})$. 


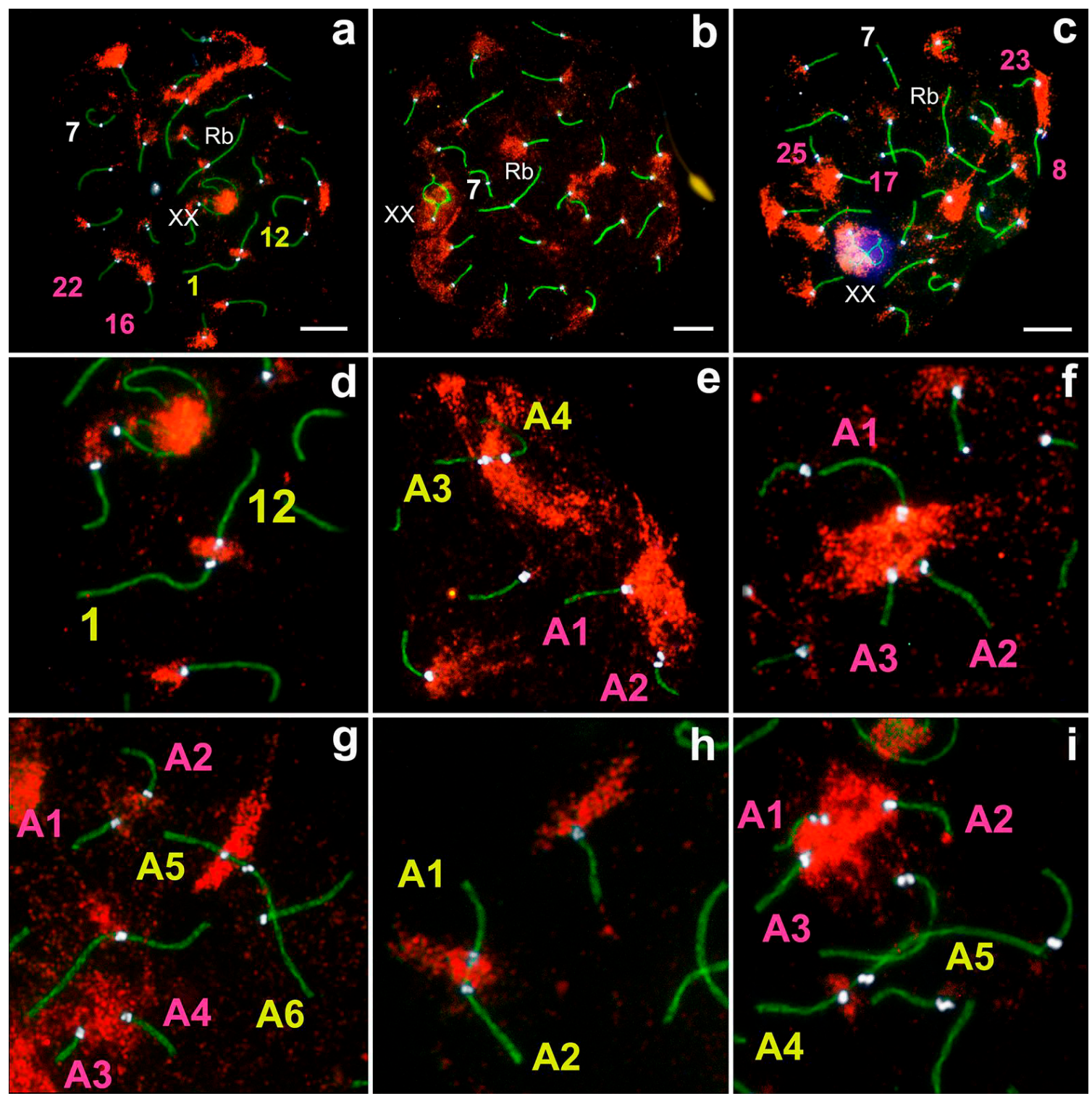

Figure 6. Location of SYCP3 (green), H3K9me3 (red), CREST (white) and gamma-H2AFX (violet) in the pachytene stage of prophase I of E. alaicus spermatocytes (a-i). Size bar $=5 \mu \mathrm{m}(\mathbf{a}-\mathbf{c})$. (d) an enlarged fragment of (a), (e-i) enlarged fragments of distinct cells. Designations A1-A6 do not correspond to numbers of chromosomes as in Figure 1. See the explanation in the text. 


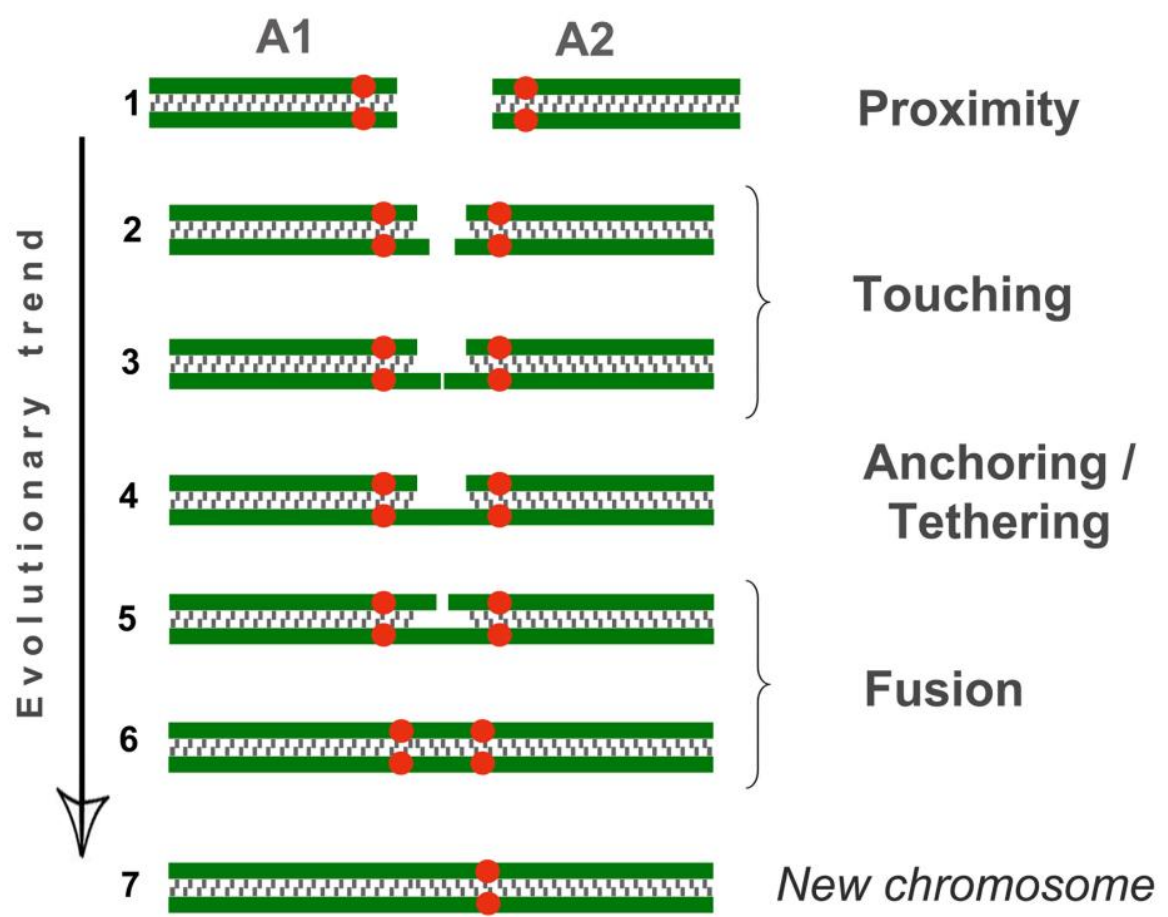

Figure 7. Different types of chromosome connections in meiotic prophase I. The scheme is based on observations of chromosome behaviors during E. alaicus meiosis. Green corresponds to SC axial/lateral elements, red dots refer to centromeres. Non-homologous acrocentrics (A1 and A2) occupy positions in the nucleus, intending to get closer (proximity, position 1). One of two lateral elements in the short arm A1 and A2 are extended (position 2), touching each other (position 3) (touching) and eventually bind together (anchoring/tethering, position 4). The other two axial elements are tightened to each other. (Position 5) and probably joined together (position 6) (fusion). After the probable binding of the two axial elements, the centromeres are located somewhat closer to each other (compare positions 5 and 6). Such dicentric bivalents were found in all oocytes of low-chromosomal forms of E. tancrei, $2 \mathrm{n}=34$ (Figure S8). In such dicentric chromosomes, one centromere may be inactivated, with a new chromosome emerging (position 7).

\section{Discussion}

In this work, we describe the variety of chromosomal interactions in male meiosis of E. alaicus. Immunocytochemical staining of spermatocytes demonstrated at least four contact types for non-homologous acrocentrics in meiotic prophase I. Starting from clustering inside the heterochromatic cloud, chromosomes demonstrate touching by the elongated axial element of the short arms, then tether by SYCP3 filaments and complete the process when tightly adjacent to each other. As a result, two acrocentrics likely represents a single bivalent with two centromeric regions.

Recently, the first report on connections between non-homologous chromosomes and SC structures was demonstrated by investigating meiosis in CD-1 male mice after irradiation [43]. The authors of this work stressed that the formation of chromosome bridges between non-homologous chromosomes differed from normal endogenous DSB interactions, which did not require connections between axial elements of homologous chromosomes. The wild ancestors of CD-1 mice were bred in a Swiss laboratory in the 1920s. Genomic studies revealed that CD-1 was mostly derived from M. domesticus [63], a species with enormous chromosome variability [64]. In this species, specific major and minor satDNA tandem repeats, which are oriented head-to-tail at centromeres [65], may facilitate fusion of mono-armed chromosomes, and build up bi-armed ones. Repeat polarity occurs in telocentric and $\mathrm{Rb}$ chromosomes, therefore it was assumed that tandem repetitive satDNA in $M$. domesticus may have been a universal pattern of chromosomal evolution. Numerous Rbs, characteristic for the species, and presumed 
random associations of bivalents in the wild type, $M$. domesticus $(2 n=40)$ spermatocytes, exemplified a wide spectrum of fusions due to the universal structure of pericentromeric satDNA in this species.

We did not analyze pericentromeric heterochromatin in Ellobius, although the numerous associations (at 'proximity' type) were similar to M. domesticus [43]. Pericentromeric heterochromatin evidently participates in chromosome contacts and fusions. A prelude at the zygotene (Figure S3) may be assigned as an example. Formation of Rbs may depend on telomere changes, especially shortening and inactivation [38]. Recently, the study of wild house mice demonstrated that telomere shortening and the number of critically short telomeres are likely to result in Rb formation [66]. Earlier, we did not detect the telomeric sequences in centromeric regions of numerous $\mathrm{Rbs}$, including $\mathrm{Rb}(2.11)$, in E. tancrei and E. talpinus hybrids [49]. The lack of signal may be explained by elimination as well as inactivation of telomere fragments. The study should be continued in E. alaicus.

Contrary to mouse experiments [43], where chromosome contacts were discovered after gamma radiation, E. alaicus came from intact natural habitats, close to terra typica of the species. Numerous and various chromosomal contacts, the enormous number of cells with such chromosome 'dance' in all studied males demonstrated an internal background for evolutionary changes. In natural E. alaicus populations, we detected [50] four different $\mathrm{Rb}$ translocations $\mathrm{Rb}(2.11), \operatorname{Rb}(1.3), \mathrm{Rb}(4.9)$, $\mathrm{Rb}(3.10)$ in distinct combinations, with $2 \mathrm{n}$ from 52 to 48 . A small number of chromosomal associations in mitotic metaphases, which we demonstrated now for animals with a single pair of $\operatorname{Rb}(2.11)$, indirectly confirmed the leading role of changes in the meiotic prophase I. We revealed differences in mitotic cell divisions for fibroblast and chondrocyte cultures. Cell culture often demonstrates unstable karyotype structures and distinct abnormality types and frequencies $[67,68]$. This assumption was our rationale for comparing data on chromosome numbers and behaviors using bone marrow slides, and two different cell culture approaches. Fibroblasts mostly retained $2 \mathrm{n}=52$, and numerous polyploid cells. Chondrocyte cultures appeared to be more fragile and demonstrated distinct changes as micronuclei, disturbed anaphases, massive chromosome changes, and associations (Figures S1 and S2). The evolutionary significance of such mutations is incredible if such events appear in the germline [32,69]. The picture of chromosomal re-assemblage (Figure S1) may be an example of chromothripsis, which combines chromosome shattering and fusion [70].

In mitotic cells, we observed two centromeres and two blocks of heterochromatin in the association of two small acrocentrics (Figure S1c,e). Previously, in the pachytene, we observed a small metacentric with two centromeres in all studied animals from natural E. tancrei populations, $2 \mathrm{n}=34$ (as in Figure S8). E. tancrei demonstrates a wide spectrum of homologous and non-homologous Robertsonian metacentrics in natural populations [51]. We suggest that dicentric chromosome formation in natural populations of this species, confirms the 'contact first in meiosis' model.

Although we had no meiotic data to prove double-stranded DNA breaks and chromosome reassembling, we demonstrated that the 'contact-first' scheme may be applicable to meiotic translocation mechanisms. Another question-the fate of small arms of acrocentric chromosomes, which are apparently kept in fused chromosomes (Figure 4e,f and Figure 5c) - is closely related to the role and evolution of the centromere. As previously mentioned, we supposed the neocentromere origin was a crucial step for E. tancrei and E. alaicus genome evolution. In cases of 'fused' chromosomes of E. alaicus, we revealed two distinct centromere signals using CREST immunostaining. The question of the further fate of two centromeres and chromosome fragments between them is now open, and the study should be continued.

Considering that mitosis and meiosis data are consistent, we can argue for the essential role of heterochromatin. In mouse spermatocytes, heterochromatin preserves the association of homologous centromeres and promotes faithful chromosome segregation in meiosis I [71]. Heterochromatin, in maintaining genome stability [72], may be a focal point for changes. We demonstrated that a 'proximity' to fuse correlated with the heterochromatin affinity of non-homologous chromosomes. Chromosomes were located around the H3K9me3-heterochromatin cloud (Figure 6f,i), similar to telocentric associations in mice [44]. Clustering of heterochromatic regions inside the H3K9me3 clouds 
was demonstrated for different sets of acrocentrics in Mus musculus domesticus either for the wild type $2 \mathrm{n}=40$ or for different forms with $\operatorname{Rbs}[44,73,74]$. This clustering could be the background of the translocations. However, no data on contacting chromosomes were published, except the gamma radiation treatment caused the formation of bridges between chromosomes [43]. Earlier, we described the participation of heterochromatin of short chromosome arms in the formation of SC chains in mole voles heterozygous for multiple Rbs [75].

High natural variability along with the rapid fixation of new translocations and specific contacts of non-homologous chromosomes in meiosis, which we demonstrated for E. alaicus, built a promising background to change the model for the mechanism of translocations from the 'contact first' to the 'contact first in meiosis'.

The evolutionary significance of meiosis as a tool to increase recombinational diversity is balanced by its function as a mechanism for purifying selection [76]. Meiotic checkpoints block cell cycle progression in response to defects and preclude abnormal chromosome segregation. Nevertheless, creative meiosis became apparent if we apply the 'contact-first' model for meiotic prophase I, as we demonstrated for a unique rodent species, which entered the stage of Robertsonian translocations emergence.

Supplementary Materials: The following are available online at http://www.mdpi.com/2073-4425/11/4/386/s1, Figure S1: Mitotic chromosomes of Ellobius alaicus, Figure S2: Aberrations in mitosis of Ellobius alaicus, Figure S3: Zygotene spermatocyte of E.alaicus, Figure S4: Different chromosome combinations in pachytene spermatocytes of E.alaicus, Figure S5: Different chromosome combinations in pachytene spermatocytes of E.alaicus, Figure S6: Location of SYCP3, H3K9me3, CREST and chromatin configuration (DAPI) in zygotene-pachytene stages of prophase I of E. alaicus spermatocytes, Figure S7: Location of SYCP3, H3K9me3, CREST, and chromatin configuration (DAPI) in pachytene-diakinesis stages of the prophase I of E. alaicus spermatocytes, Figure S8: A pachytene oocyte of $E$. tancrei, $2 \mathrm{n}=34, \mathrm{NF}=56$.

Author Contributions: Conceptualization, S.M., O.K., I.B.; methodology, O.K., I.B., S.M.; investigation, S.M., I.B., E.A. and A.B.; writing, I.B., S.M., E.A., A.B., and O.K.; visualization, S.M., and I.B.; funding acquisition, S.M., I.B.; supervision, O.K., and I.B. All the authors read and approved the final text of the submitted manuscript and the supporting information. All authors have read and agreed to the published version of the manuscript.

Funding: This research was partially supported by the research grants of the Russian Foundation for Basic Research Nos. 20-34-70027, 20-04-00618; VIGG RAS State Assignment Contract (S.M, O.K), and IDB RAS State Assignment for Basic Research (A.B., E.A., I.B.).

Acknowledgments: We thank the Genetic Polymorphisms Core Facility of the Vavilov Institute of General Genetics of the Russian Academy of Sciences, Moscow, for the possibility to use their microscopes. We are grateful to Core Centrum of the Koltzov Institute of Developmental Biology RAS for the possibility of using samples from the Cell culture collection and the Joint collection of wildlife tissues for fundamental, applied, and environmental researches.

Conflicts of Interest: The authors declare no conflict of interest. The funders had no role in the design of the study; in the collection, analyses, or interpretation of data; in the writing of the manuscript, or in the decision to publish the results.

\section{References}

1. Cremer, T.; Cremer, C. Chromosome territories, nuclear architecture and gene regulation in mammalian cells. Nat Rev. Genet. 2001, 2, 292-301. [CrossRef]

2. Cremer, T.; Cremer, C. Rise, fall and resurrection of chromosome territories: A historical perspective. Part I. The rise of chromosome territories. Eur. J. Histochem. 2006, 50, 161-176. [PubMed]

3. Cremer, T.; Cremer, M. Chromosome territories. Cold Spring Harb. Perspect. Biol. 2010, 2, a003889. [CrossRef]

4. Solovei, I.; Kreysing, M.; Lanctôt, C.; Kösem, S.; Peichl, L.; Cremer, T.; Guck, J.; Joffe, B. Nuclear architecture of rod photoreceptor cells adapts to vision in mammalian evolution. Cell 2009, 137, 356-368. [CrossRef] [PubMed]

5. Tan, L.; Xing, D.; Chang, C.H.; Li, H.; Xie, X.S. Three-dimensional genome structures of single diploid human cells. Science 2018, 361, 924-928. [CrossRef] [PubMed]

6. Boveri, T. Concerning the origin of malignant tumours by Theodor Boveri. Translated and annotated by Henry Harris. J. Cell Sci. 2008, 121 (Suppl. 1), 1-84. [CrossRef] [PubMed] 
7. Mai, S. The three-dimensional cancer nucleus. Genes Chromosomes Cancer 2019, 58, 462-473. [CrossRef] [PubMed]

8. Meaburn, K.J.; Misteli, T.; Soutoglou, E. Spatial genome organization in the formation of chromosomal translocations. Semin. Cancer Biol. 2007, 17, 80-90. [CrossRef]

9. Heyer, E.E.; Deveson, I.W.; Wooi, D.; Selinger, C.I.; Lyons, R.J.; Hayes, V.M.; O’Toole, S.A.; Ballinger, M.L.; Gill, D.; Thomas, D.M.; et al. Diagnosis of fusion genes using targeted RNA sequencing. Nat. Commun. 2019, 10, 1388. [CrossRef]

10. Salgueiro, L.; Buccitelli, C.; Rowald, K.; Somogyi, K.; Kandala, S.; Korbel, J.O.; Sotillo, R. Acquisition of chromosome instability is a mechanism to evade oncogene addiction. EMBO Mol. Med. 2020, 12, e10941. [CrossRef]

11. Maciejowski, J.; Li, Y.; Bosco, N.; Campbell, P.J.; de Lange, T. Chromothripsis and kataegis induced by telomere crisis. Cell 2015, 163, 1641-1654. [CrossRef] [PubMed]

12. Pellestor, F. Chromothripsis and the Macroevolution Theory. Methods Mol. Biol. 2018, 1769, 43-49. [PubMed]

13. Pellestor, F.; Gatinois, V. Chromoanagenesis: A piece of the macroevolution scenario. Mol. Cytogenet. 2020, 13, 3. [CrossRef] [PubMed]

14. Matthey, R. Les Chromosomes des Vértebrés; F. Rouge: Lausanne, Suisse, 1949.

15. White, M.J.D. Modes of Speciation; W.H. Freeman and Co.: New York, NY, USA, 1978.

16. King, M. Species Evolution: The Role of Chromosome Change; Cambridge University Press: Cambridge, UK, 1993.

17. Faria, R.; Navarro, A. Chromosomal speciation revisited: Rearranging theory with pieces of evidence. Trends Ecol. Evol. 2010, 25, 660-669. [CrossRef]

18. Ruiz-Herrera, A.; Farré, M.; Robinson, T.J. Molecular cytogenetic and genomic insights into chromosomal evolution. Heredity 2012, 108, 28-36. [CrossRef]

19. Graves, J.A. Did sex chromosome turnover promote divergence of the major mammal groups? De novo sex chromosomes and drastic rearrangements may have posed reproductive barriers between monotremes, marsupials and placental mammals. Bioessays 2016, 38, 734-743. [CrossRef]

20. Evgen'ev, M.B.; Zelentsova, H.; Poluectova, H.; Lyozin, G.T.; Veleikodvorskaja, V.; Pyatkov, K.I.; Zhivotovsky, L.A.; Kidwell, M.G. Mobile elements and chromosomal evolution in the virilis group of Drosophila. Proc. Natl. Acad. Sci. USA 2000, 97, 11337-11342. [CrossRef]

21. Rodriguez-Martin, B.; Alvarez, E.G.; Baez-Ortega, A.; Zamora, J.; Supek, F.; Demeulemeester, J.; Santamarina, M.; Ju, Y.S.; Temes, J.; Garcia-Souto, D.; et al. Pan-cancer analysis of whole genomes identifies driver rearrangements promoted by LINE-1 retrotransposition. Nat. Genet. 2020, 52, 306-319. [CrossRef]

22. Brown, J.D.; Mitchell, S.E.; O'Neill, R.J. Making a long story short: Noncoding RNAs and chromosome change. Heredity 2012, 108, 42-49. [CrossRef]

23. Aten, J.A.; Stap, J.; Krawczyk, P.M.; van Oven, C.H.; Hoebe, R.A.; Essers, J.; Kanaar, R. Dynamics of DNA double-strand breaks revealed by clustering of damaged chromosome domains. Science 2004, 303, 92-95. [CrossRef]

24. McCord, R.P.; Balajee, A. 3D genome organization influences the chromosome translocation pattern. In Chromosome Translocation; Springer: Singapore, 2018; pp. 113-133.

25. Branco, M.R.; Pombo, A. Intermingling of chromosome territories in interphase suggests role in translocations and transcription-dependent associations. PLoS Biol. 2006, 4, e138. [CrossRef] [PubMed]

26. Szczepińska, T.; Rusek, A.M.; Plewczynski, D. Intermingling of chromosome territories. Genes Chromosomes Cancer 2019, 58, 500-506. [CrossRef] [PubMed]

27. Farré, M.; Robinson, T.J.; Ruiz-Herrera, A. An Integrative Breakage Model of genome architecture, reshuffling and evolution: The Integrative Breakage Model of genome evolution, a novel multidisciplinary hypothesis for the study of genome plasticity. BioEssays 2015, 37, 479-488. [CrossRef] [PubMed]

28. Klein, I.A.; Resch, W.; Jankovic, M.; Oliveira, T.; Yamane, A.; Nakahashi, H.; Di Virgilio, M.; Bothmer, A.; Nussenzweig, A.; Robbiani, D.F.; et al. Translocation-capture sequencing reveals the extent and nature of chromosomal rearrangements in B lymphocytes. Cell 2011, 147, 95-106. [CrossRef]

29. Gothe, H.J.; Minneker, V.; Roukos, V. Dynamics of double-strand breaks: Implications for the formation of chromosome translocations. In Chromosome Translocation; Springer: Singapore, 2018; pp. 27-38. 
30. Schrank, B.; Gautier, J. Assembling nuclear domains: Lessons from DNA repair. J. Cell Biol. 2019, 218, 2444-2455. [CrossRef]

31. Finn, E.H.; Misteli, T. Molecular basis and biological function of variability in spatial genome organization. Science 2019, 365, eaaw9498. [CrossRef]

32. Kim, S.; Peterson, S.E.; Jasin, M.; Keeney, S. Mechanisms of germ line genome instability. Semin. Cell Dev. Biol. 2016, 54, 177-187. [CrossRef]

33. Robertson, W.R.B. Chromosome studies. I. Taxonomic relationships shown in the chromosomes of Tettigidae and Acrididae: V-shaped chromosomes and their significance in Acrididae, Locustidae, and Gryllidae: Chromosomes and variation. J. Morphol. 1916, 27, 179-331. [CrossRef]

34. Hamerton, J.L.; Canning, N.; Ray, M.; Smith, S. A cytogenetic survey of 14,069 newborn infants: I. Incidence of chromosome abnormalities. Clin. Genet. 1975, 8, 223-243. [CrossRef]

35. Page, S.L.; Shatter, L.G. Nonhomologous Robertsonian translocations form predominantly during female meiosis. Nat. Genet. 1997, 15, 231-232. [CrossRef]

36. Page, S.L.; Shin, J.C.; Han, J.Y.; Andy Choo, K.H.; Shaffer, L.G. Breakpoint diversity illustrates distinct mechanisms for Robertsonian translocation formation. Hum. Mol. Genet. 1996, 5, 1279-1288. [CrossRef] [PubMed]

37. Richardson, C.; Moynahan, M.E.; Jasin, M. Double-strand break repair by interchromosomal recombination: Suppression of chromosomal translocations. Genes Dev. 1998, 12, 3831-3842. [CrossRef] [PubMed]

38. Slijepcevic, P. Telomeres and mechanisms of Robertsonian fusion. Chromosoma 1998, 107, 136-140. [CrossRef] [PubMed]

39. Garagna, S.; Broccoli, D.; Redi, C.A.; Searle, J.B.; Cooke, H.J.; Capanna, E. Robertsonian metacentrics of the mouse lose telomeric sequences but retain some minor satellite DNA in the pericentromeric area. Chromosoma 1995, 103, 685-692. [CrossRef] [PubMed]

40. Nanda, I.; Schneider-Rasp, S.; Winking, H.; Schmid, M. Loss of telomeric sites in the chromosomes of Mus musculus domesticus (Rodentia: Muridae) during Robertsonian rearrangements. Chromosom. Res. 1995, 3, 399-409. [CrossRef] [PubMed]

41. Meyne, J.; Baker, R.J.; Hobart, H.H.; Hsu, T.C.; Ryder, O.A.; Ward, O.G.; Wiley, J.E.; Wurster-Hill, D.H.; Yates, T.L.; Moyzis, R.K. Distribution of nontelomeric sites of (TTAGGG)n telomeric sequences in vertebrate chromosomes. Chromosoma 1990, 99, 3-10. [CrossRef]

42. Blasco, M.A.; Lee, H.; Hande, M.P.; Samper, E.; Lansdorp, P.M.; De Pinho, R.A.; Greider, C.W. Telomere shortening and tumor formation by mouse cells lacking telomerase RNA. Cell 1997, 91, 25-34. [CrossRef]

43. Enguita-Marruedo, A.; Martín-Ruiz, M.; García, E.; Gil-Fernández, A.; Parra, M.T.; Viera, A.; Rufas, J.S.; Page, J. Transition from a meiotic to a somatic-like DNA damage response during the pachytene stage in mouse meiosis. PLoS Genet. 2019, 15, e1007439. [CrossRef]

44. Berríos, S.; Manterola, M.; Prieto, Z.; López-Fenner, J.; Page, J.; Fernández-Donoso, R. Model of chromosome associations in Mus domesticus spermatocytes. Biol. Res. 2010, 43, 275-285. [CrossRef]

45. Garagna, S.; Page, J.; Fernandez-Donoso, R.; Zuccotti, M.; Searle, J.B. The Robertsonian phenomenon in the house mouse: Mutation, meiosis and speciation. Chromosoma 2014, 123, 529-544. [CrossRef]

46. Searle, J.B.; Polly, P.D.; Zima, J. (Eds.) Shrews, Chromosomes and Speciation; Cambridge University Press: Cambridge, UK, 2019; p. 488.

47. Lyapunova, E.A.; Vorontsov, N.N.; Korobitsina, K.V.; Ivanitskaya, E.Y.; Borisov, Y.M.; Yakimenko, L.V.; Dovgal, V.Y. A Robertsonian fan in Ellobius talpinus. Genetica 1980, 52/53, 239-247. [CrossRef]

48. Bakloushinskaya, I.; Matveevsky, S. Unusual ways to lost Y chromo-some and survive with changed autosomes: A story of mole voles Ellobius (Mammalia, Rodentia). OBM Genet. 2018, 2, 023. [CrossRef]

49. Bakloushinskaya, I.Y.; Matveevsky, S.N.; Romanenko, S.A.; Serdukova, N.A.; Kolomiets, O.L.; Spangenberg, V.E.; Lyapunova, E.A.; Graphodatsky, A.S. A comparative analysis of the mole vole sibling species Ellobius tancrei and E. talpinus (Cricetidae, Rodentia) through chromosome painting and examination of synaptonemal complex structures in hybrids. Cytogenet. Genome Res. 2012, 136, 199-207. [CrossRef] [PubMed]

50. Bakloushinskaya, I.; Lyapunova, E.A.; Saidov, A.S.; Romanenko, S.A.; O’Brien, P.C.; Serdyukova, N.A.; Ferguson-Smith, M.A.; Matveevsky, S.; Bogdanov, A.S. Rapid chromosomal evolution in enigmatic mammal with XX in both sexes, the Alay mole vole Ellobius alaicus Vorontsov et al., 1969 (Mammalia, Rodentia). Comp. Cytogenet. 2019, 13, 147. [CrossRef] 
51. Romanenko, S.A.; Lyapunova, E.A.; Saidov, A.S.; O’Brien, P.; Serdyukova, N.A.; Ferguson-Smith, M.A.; Graphodatsky, A.S.; Bakloushinskaya, I. Chromosome Translocations as a Driver of Diversification in Mole Voles Ellobius (Rodentia, Mammalia). IJMS 2019, 20, 4466. [CrossRef]

52. Matveevsky, S.N. Signs of Sexual Dimorphism in Meiosis and Karyotype Variability of Mole Vole Ellobius (Rodentia, Mammalia). Ph.D. Thesis, NI Vavilov Institute of General Genetics of Russian Academy of Science, Moscow, Russia, 2011; pp. 1-172. (In Russian).

53. Ford, C.E.; Hamerton, J.L. A colchicine, hypotonic citrate, squash sequence for mammalian chromosomes. Stain Technol. 1956, 31, 247-251. [CrossRef]

54. Sumner, A.T. A simple technique for demonstrating centromeric heterochromatin. Exp. Cell Res. 1972, 75, 304-306. [CrossRef]

55. Peters, A.H.F.M.; Plug, A.W.; van Vugt, M.J.; de Boer, P. A drying-down technique for the spreading of mammalian meiocytes from the male and female germ line. Chromosome Res. 1997, 5, 66-71. [CrossRef]

56. Page, J.; Berríos, S.; Rufas, J.S.; Parra, M.T.; Suja, J.Á.; Heyting, C.; Fernández-Donoso, R. The pairing of X and $\mathrm{Y}$ chromosomes during meiotic prophase in the marsupial species Thylamys elegans is maintained by a dense plate developed from their axial elements. J. Cell Sci. 2003, 116, 551-560. [CrossRef]

57. Matveevsky, S.; Bakloushinskaya, I.; Tambovtseva, V.; Romanenko, S.; Kolomiets, O. Analysis of meiotic chromosome structure and behavior in Robertsonian heterozygotes of Ellobius tancrei (Rodentia, Cricetidae): A case of monobrachial homology. Comp. Cytogenet. 2015, 9, 691. [CrossRef]

58. Matveevsky, S.; Kolomiets, O.; Bogdanov, A.; Hakhverdyan, M.; Bakloushinskaya, I. Chromosomal evolution in mole voles Ellobius (Cricetidae, Rodentia): Bizarre sex chromosomes, variable autosomes and meiosis. Genes 2017, 8, 306. [CrossRef] [PubMed]

59. Kolomiets, O.L.; Matveevsky, S.N.; Bakloushinskaya, I.Y. Sexual dimorphism in prophase I of meiosis in the Northern mole vole (Ellobius talpinus Pallas, 1770) with isomorphic (XX) chromosomes in males and females. Comp. Cytogenet. 2010, 4, 55-66. [CrossRef]

60. Kolomiets, O.L.; Vorontsov, N.N.; Lyapunova, E.A.; Mazurova, T.F. Ultrastructure, meiotic behavior, and evolution of sex chromosomes of the genus Ellobius. Genet. 1991, 84, 179-189. [CrossRef]

61. Matveevsky, S.; Bakloushinskaya, I.; Kolomiets, O. Unique sex chromosome systems in Ellobius: How do male XX chromosomes recombine and undergo pachytene chromatin inactivation? Sci. Rep. 2016, 6, 29949. [CrossRef] [PubMed]

62. Nakayama, J.; Rice, J.C.; Strahl, B.D.; Allis, C.D.; Grewal, S.I. Role of histone H3 lysine 9 methylation in epigenetic control of heterochromatin assembly. Science 2001, 292, 110-113. [CrossRef] [PubMed]

63. Aldinger, K.A.; Sokoloff, G.; Rosenberg, D.M.; Palmer, A.A.; Millen, K.J. Genetic variation and population substructure in outbred CD-1 mice: Implications for genome-wide association studies. PLoS ONE 2009, 4, e4729. [CrossRef] [PubMed]

64. Castiglia, R. Sympatric sister species in rodents are more chromosomally differentiated than allopatric ones: Implications for the role of chromosomal rearrangements in speciation. Mammal Rev. 2014, 44, 1-4. [CrossRef]

65. Garagna, S.; Marziliano, N.; Zuccotti, M.; Searle, J.B.; Capanna, E.; Redi, C.A. Pericentromeric organization at the fusion point of mouse Robertsonian translocation chromosomes. Proc. Natl. Acad. Sci. USA 2001, 98, 171-175. [CrossRef]

66. Sánchez-Guillén, R.A.; Capilla, L.; Reig-Viader, R.; Martínez-Plana, M.; Pardo-Camacho, C.; Andrés-Nieto, M.; Ventura, J.; Ruiz-Herrera, A. On the origin of Robertsonian fusions in nature: Evidence of telomere shortening in wild house mice. J. Evol. Biol. 2015, 28, 241-249. [CrossRef]

67. Palumbo, E.; Russo, A. Common fragile site instability in normal cells: Lessons and perspectives. Genes Chromosomes Cancer 2019, 58, 260-269. [CrossRef]

68. Guadarrama-Ponce, R.; Aranda-Anzaldo, A. The epicenter of chromosomal fragility of Fra14A2, the mouse ortholog of human FRA3B common fragile site, is largely attached to the nuclear matrix in lymphocytes but not in other cell types that do not express such a fragility. J. Cell. Biochem. 2020, 121, 2209-2224. [CrossRef] [PubMed]

69. Fukami, M.; Shima, H.; Suzuki, E.; Ogata, T.; Matsubara, K.; Kamimaki, T. Catastrophic cellular events leading to complex chromosomal rearrangements in the germline. Clin. Genet. 2017, 91, 653-660. [CrossRef] [PubMed] 
70. Stephens, P.J.; Greenman, C.D.; Fu, B.; Yang, F.; Bignell, G.R.; Mudie, L.J.; Pleasance, E.D.; Lau, K.W.; Beare, D.; Stebbings, L.A.; et al. Massive genomic rearrangement acquired in a single catastrophic event during cancer development. Cell 2011, 144, 27-40. [CrossRef] [PubMed]

71. Eyster, C.; Chuong, H.H.; Lee, C.Y.; Pezza, R.J.; Dawson, D. The pericentromeric heterochromatin of homologous chromosomes remains associated after centromere pairing dissolves in mouse spermatocyte meiosis. Chromosoma 2019, 128, 355-367. [CrossRef]

72. Janssen, A.; Colmenares, S.U.; Karpen, G.H. Heterochromatin: Guardian of the genome. Annu. Rev. Cell Dev. Biol. 2018, 34, 265-288. [CrossRef]

73. Manterola, M.; Page, J.; Vasco, C.; Berríos, S.; Parra, M.T.; Viera, A.; Rufas, J.S.; Zuccotti, M.; Garagna, S.; Fernández-Donoso, R. A high incidence of meiotic silencing of unsynapsed chromatin is not associated with substantial pachytene loss in heterozygous male mice carrying multiple simple robertsonian translocations. PLoS Genet. 2009, 5, e1000625. [CrossRef]

74. Capilla, L.; Medarde, N.; Alemany-Schmidt, A.; Oliver-Bonet, M.; Ventura, J.; Ruiz-Herrera, A. Genetic recombination variation in wild Robertsonian mice: On the role of chromosomal fusions and Prdm9 allelic background. Proc. R. Soc. Lond. B Biol. Sci. 2014, 281, 20140297. [CrossRef]

75. Kolomiets, O.L.; Lyapunova, E.A.; Mazurova, T.F.; Yanina, I.Y.; Bogdanov, Y.F. Participation of heterochromatin in formation of synaptonemal complex chains in animals heterozygous for multiple Robertsonian translocation. Russ. J. Genet. 1986, 22, 273-283. (In Russian)

76. Lenormand, T.; Engelstädter, J.; Johnston, S.E.; Wijnker, E.; Haag, C.R. Evolutionary mysteries in meiosis. Phil. Trans. R. Soc. B 2016, 371, 20160001. [CrossRef]

(C) 2020 by the authors. Licensee MDPI, Basel, Switzerland. This article is an open access article distributed under the terms and conditions of the Creative Commons Attribution (CC BY) license (http://creativecommons.org/licenses/by/4.0/). 